\title{
Discovery of plastoquinones: a personal perspective
}

\author{
Frederick L. Crane
}

Received: 24 October 2009/Accepted: 10 February 2010/Published online: 9 March 2010

(C) Springer Science+Business Media B.V. 2010

\begin{abstract}
The discovery and the rediscovery of plastoquinone (PQ) are described together with the definition of its structure as a 2,3-dimethyl 5 solanosyl benzoquinone. The discovery, by M. Kofler, was a result of a search for Vitamin $\mathrm{K}$. Its rediscovery was made by me, when I was at The Enzyme Institute of the University of Wisconsin, analyzing animals and plants for the newly discovered coenzyme Q. In green plants, I found another lipophilic quinone in addition to coenzyme Q. Some misleading evidence suggested as if the new quinone had coenzyme $Q$ activity in mitochondria, but improved methods gave negative results. When I found that
\end{abstract}

This personal perspective was invited and edited by Govindjee, the Founding Historical Corner Editor of Photosynthesis Research. He thanks Achim Trebst for suggesting that the historical discoveries by Fred Crane be published in 'Photosynthesis Research' as a continuation of articles in 'Discoveries in Photosynthesis' (edited by Govindjee et al.), volume 20, Advances in Photosynthesis and Respiration, Springer, Dordrecht, 2005 (http://www.springer.com/ life+sci/plant+sciences/book/978-1-4020-3323-0). Further, Govindjee expresses his appreciation to Hartmut Lichtenthaler, Richard Dilley, and Achim Trebst for reading the manuscript and making valuable comments.

\section{F. L. Crane}

Department of Biological Sciences, Purdue University,

West Lafayette, IN 47906, USA

F. L. Crane ( $\square)$

610 Countryside Dr, Metamora, IL 61548, USA

e-mail: flccoq10@aol.com the quinone was concentrated in chloroplasts, I considered a role for it in photosynthesis analogous to the role of coenzyme $\mathrm{Q}$ in mitochondria. After moving to the Chemistry Department, University of Texas at Austin, I used a plain light bulb and some spinach chloroplasts to show that PQ could be involved in photosynthetic redox reactions. This effect was supported by Norman Bishop's restoration of chloroplast electron transport after solvent extraction, with PQ and photoreduction studies by E. R. Redfern and J. Friend in R. A. Morton's laboratory in Liverpool, UK. We also found an additional analog of PQ in addition to a second analog found in Wisconsin. We called the new analogs PQB and PQC. Although we found some restoration effects with PQC, the discovery by W. T. Griffiths in Morton's laboratory, that PQB and PQC consisted of six forms of PQ each, made it more likely that the new analogs were breakdown products. Morton's group established the structure of the PQCs as a series of PQs, with a hydroxyl group on the prenyl side chain, and the PQB series as having fatty acids esterified to the hydroxyl groups of PQC. Possible functions of the analogs are also discussed in this article.

Keywords M. Kofler · David Green - Coenzyme Q . Plastoquinones · Photosynthesis · Chloroplast · Carotene · Antioxidant · Redox control

$\begin{array}{ll}\text { Abbreviations } \\ \text { DBMIB } & \text { Dibromthymoquinone } \\ \text { DCPIP } & \text { Dichloroindophenol } \\ \text { DCMU } & \text { 3-(3,4-Dichloro-phenyl)-1,1 dimethyl urea } \\ \text { PQ } & \text { Plastoquinone } \\ \text { PQA } & \text { Plastoquinone A } \\ \text { PQB } & \text { Plastoquinone B } \\ \text { PQC } & \text { Plastoquinone C }\end{array}$




\section{The discovery of the plastoquinone}

Plastoquinone (PQ) was discovered by Kofler (1946) during a search for compounds with Vitamin $\mathrm{K}$ activity in alfalfa. The search led to a compound which had chromatographic properties of Vitamin K; it also gave a DamKarrer ${ }^{1}$ color reaction with potassium ethoxide that was also consistent with it being Vitamin K. Further determination of spectral and chemical properties indicated that it was a tri or tetra substituted benzoquinone with a long isoprenoid side chain. A negative Cravens ${ }^{2}$ test for an unsubstituted site on the quinone ring indicated a tetra substituted benzoquinone. Later examination indicated a positive test for a tri-substituted quinone (Kofler et al. 1959; Isler et al. 1961).The structure of the prenyl side chain remained unclear. At first, it was thought to be 10 prenyl or 50 carbon-long because solensol, which was used as the long chain compound in the synthesis, was thought to have 50 carbons. However, after the synthesis of coenzyme Q9, instead of coenzyme Q10, and when solanosol was used as a side chain, it was discovered that PQ with a solanosol side chain was identical with a natural PQ and, therefore, had a 45 carbon chain made up of nine isoprene units (Folkers et al. 1961; also see Trenner et al. 1959). This was in agreement with Isler et al. (1961). These studies defined Kofler's quinone or Q254 (see below) or PQ as 2,3 di-methyl 5 solanosyl benzoquinone (Fig. 1). In his original work on PQ, Kofler (1946) had measured the PQ content in leaves of six plants for which Dam-Karrer reaction had established Vitamin $\mathrm{K}$ content by his biological assay of blood clotting time in chickens. Kofler (1946) found that $\mathrm{PQ}$ in leaves ranged from $150 \mathrm{mg} / \mathrm{kg}$ dry weight for alfalfa (or oats) to $400 \mathrm{mg} / \mathrm{kg}$ for fir needles and a maximum of $1,000 \mathrm{mg} / \mathrm{kg}$ in horse chestnut. In comparison with the content of Vitamin K, established by the biological assay, the PQ was 3-5 times greater in amount. When PQ was tested in chickens for Vitamin $\mathrm{K}$ activity, $1 \mathrm{mg}$ Vitamin $\mathrm{K}$ was more effective than $500 \mathrm{mg} \mathrm{PQ}$. (The clotting time for Vitamin $\mathrm{K}$ was $2.3 \mathrm{~min}$ vs. $30 \mathrm{~min}$ for PQ.) With the lack of Vitamin K activity, work on PQ was stopped until the discovery of coenzyme Q.

\footnotetext{
${ }^{1}$ Dam-Karrar test In this test, alcoholic solution of quinones is treated with $3 \% \mathrm{KOH}$ in methanol to produce a blue color. Henrik Dam (1895-1976; Nobel Prize in Medicine) was the discoverer of Vitamin K. He had published on a color test, for Vitamin K, with Paul Karrer (1889-1971; Nobel Prize in Chemistry for the chemistry of Carotenoids and other plant pigments).

2 Craven's test It is a color test for certain quinones (Craven 1931); quinones with an unsubstituted position on the ring produce a blue color when treated with ammonia and ethyl cyanoacetate (see Crane and Dilley (1963) where this test is described in details).
}<smiles>CC(C)=CCCC1=CC(=O)C(C)=C(C)C1=O</smiles><smiles>CC(C)=CCC1=C(C)C(=O)c2ccccc2C1=O</smiles><smiles>CC1=C(C)C(=O)C(CCC(C)(O)CC2(C)CC2)=C(C)C1=O</smiles>

Fig. 1 Structure of plastoquinone A (top), Vitamin K (Vitamin K1) (middle), and $\alpha$ tocopherylquinone (bottom). Vitamin $\mathrm{K}$ functions in photosystem I, tocopherylquinone is in chloroplasts but has no known function

\section{The re-discovery of the plastoquinone}

The rediscovery of PQ came about as a direct result of the discovery of coenzyme Q (Crane et al. 1957; Morton 1959) and the study of coenzyme Q distribution in diverse species. We had relatively simple procedures for the analysis of coenzyme Q. We started either with its direct extraction with a solvent mixture or by saponification in the presence of pyrogallol followed by extraction with hydrocarbon solvents and chromatography on sodium aluminum silicate (Decalso). The solvent was evaporated and the yellow oil taken up in ethanol to run the absorption spectrum followed by the addition of borohydride to reduce the quinone to the hydroquinone. The shift in the absorption maximum, which we observed, is rather characteristic for quinones (Fig. 2). Chromatography on silicone-coated paper was developed by Lester and Ramasarma (1959) to identify the side chain variation as in coenzyme Q10, Q9, Q8, or Q7, where each number represents the number of isoprene units in the side chain.

I found a compound, in a lipid extract from heart mitochondria, which had an absorption spectrum of a quinone. It was December 3, 1956. This compound turned out to be a coenzyme Q. The first evidence of another lipophilic quinone was an absorption peak at $260 \mathrm{~nm}$; the compound, in an extract from wheat germ, prepared on June 3, 1957, was reduced by borohydride. I don't recall if anything further was done with this fraction. The next recorded event was the separation of a compound, from cauliflower buds, that had a 


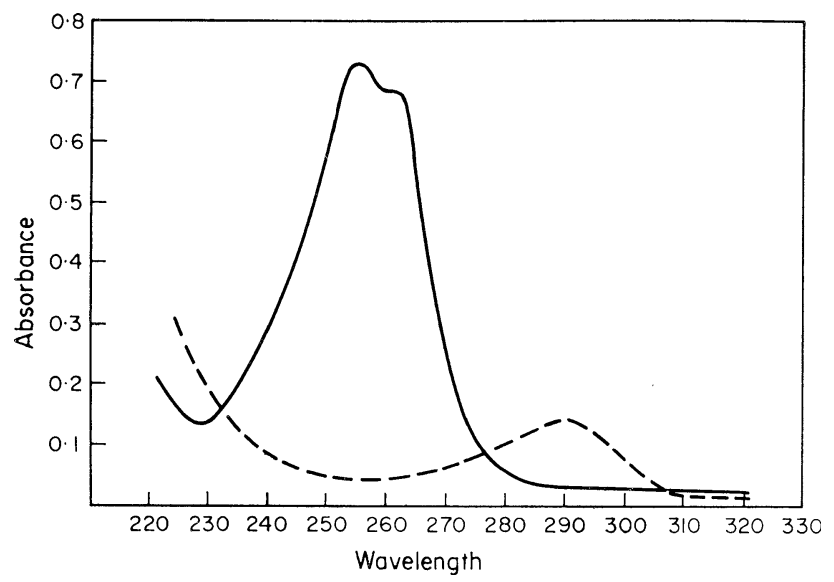

Fig. 2 Absorbance spectra of plastoquinone A. Curve with a peak at $255 \mathrm{~nm}$ is oxidized plastoquinone. Curve with a peak at $290 \mathrm{~nm}$ is plastoquinone reduced with borohydride. Plastoquinones $\mathrm{B}$ and $\mathrm{C}$ have the same spectra

characteristic absorption spectrum of a quinone. The new quinone had an absorbance peak at $254 \mathrm{~nm}$; thus, we called it Q254 (Fig. 2), whereas coenzyme Q was Q275 according to its absorbance peak at $275 \mathrm{~nm}$. Surprisingly, we found more Q254 than Q275 in the cauliflower buds $[0.015 \mathrm{mg} / \mathrm{g}$ Q254 compared to $0.01 \mathrm{mg} / \mathrm{g}$ Q275 (on dry weight basis)]. This was found on November 9, 1957. It was not until the Spring of 1958 that I discovered it in spinach leaves $(0.012 \mathrm{mg} / \mathrm{g}$ fresh weight or $\sim 0.12 \mathrm{mg} / \mathrm{g}$ dry weight $)$; this quantity was more than in the cauliflower buds. On April 23, 1958, we prepared Q254 by direct solvent extraction of dried alfalfa, and on April 24 of the same year, we prepared Q254 from saponified alfalfa. We used both procedures to check for artifacts arising during preparation. Both procedures gave the same product. We also did a large scale direct extraction using a commercial kitchen mixer with $10 \mathrm{lb}$ of dry alfalfa and 1.5 gallon heptane set out in the car parking lot to stir for a few hours. We were lucky it didn't blow up!

\section{What is the function of plastoquinone, and where is it located?}

The discovery of a new quinone raised the question of where it might fit into the electron transport chain or if it had function in protonation. In a sense, both possibilities turned out to be right as this quinone carries electrons as well as protons. Our first tests for its function were influenced by our then current study of coenzyme Q function in the mitochondrial electron transport (Crane 1961). On January 11, 1958, we tested Q254 for restoration of succinoxidase in isooctane-extracted mitochondria and found that it gave partial restoration of activity (Table 1). On April 10, 1958, we tested Q254 reduction in cauliflower
Table 1 Restoration of succinoxidase in isooctane extracted heart mitochondrial membranes by Coenzyme Q, Vitamin K1 and quinones Q254 from cauliflower buds

\begin{tabular}{llll}
\hline Additions & $\begin{array}{l}\text { Succinoxidase } \\
\left(\begin{array}{l}\text { micromoles } \\
\left.\mathrm{min}^{-1} \mathrm{mg}^{-1}\right)\end{array}\right.\end{array}$ & $\mathrm{Q}\left(\mathrm{mg} \mathrm{m}^{-1}\right)$ & $\begin{array}{l}\text { Activity } \\
\text { per mg Q }\end{array}$ \\
\hline None & 0.07 & & \\
Q275 & 0.66 & 0.05 & 2.3 \\
Q275 & 0.70 & 0.1 & 6.3 \\
Vitamin K1 & 0.06 & 3 & 0 \\
Q254 & 0.18 & 0.025 & 4.4 \\
Q254 & 0.12 & 0.05 & 1.0 \\
\hline
\end{tabular}

Assay as in Crane (1959b). This type of experiment gave indication of a role for Q254 (plastoquinone) in mitochondria. Unfortunately, isooctane extraction can give restoration with various lipids and can be misleading. Unpublished experiment of January 11, 1958

mitochondria with succinate; it was reduced as effectively as coenzyme Q was (Table 2). During 1958, while searching for conditions and factors required for coenzyme $\mathrm{Q}$ function in solvent-extracted mitochondria, we found that Q254 had some coenzyme Q like activity in (beef) heart mitochondria after isooctane extraction. The Folkers' group at Merck Company also provided short side chain Q254 analogs which also restored some succinoxidase after isooctane extraction. All Q254 analogs were inactive compared to the coenzyme $\mathrm{Q}$ in extracted succinic dehydrogenase preparations. Our conclusion was that a role in succinoxidase was unlikely. The failure to detect Q254 in animals brought up the question of a possible role in photosynthesis (Lester and Crane 1959). On May 4, 1958 (Experiment \#F253 of the author, unpublished), we found $0.00014 \mathrm{mg}$ Q275 per $\mathrm{g}$ fresh white potato, but no Q254. This raised the following questions:

1. Is Q254 preferentially associated with chloroplasts?

2. Is Q254 mostly found in green shoots compared to roots?

Table 2 Reduction of Q275 (Coenzyme Q) and Q254 (plastoquinone) by succinic dehydrogenase (labeled as protein) in cauliflower mitochondria; Q275 was $0.05 \mathrm{mg} / \mathrm{ml}$ and Q254 was $0.1 \mathrm{mg} / \mathrm{ml}$, as in Hatefi et al. (1959)

\begin{tabular}{lll}
\hline Additions & Cauliflower mitochondria & OD270 \\
\hline Q275 & 0 & 1.08 \\
Q275 & $2.7 \mathrm{mg}$ protein & 0.580 \\
\hline Additions & Cauliflower mitochondria & OD254 \\
\hline Q254 & 0 & 1.100 \\
Q254 & $2.7 \mathrm{mg}$ protein & 0.758
\end{tabular}

Incubation time was $30 \mathrm{~min}$. The reduction indicated a possible role for Q254 in plant mitochondria. Unpublished experiment of April 10, 1958 
3. Is Q254 mostly found in the green parts of variegated leaves?

During the early summer of 1958, I found time to study the distribution of Q254 in different samples (Crane 1959a). In answer to the Question 1 raised, we found that in membranes separated by differential centrifugation from a spinach leaf homogenate, Q254 accompanied chlorophyll and Q275 accompanied succinoxidase (Fig. 3) indicating that Q254 could be involved in photosynthesis. In answer to Question 2, we found that the shoots have $4.3 \times$ as much Q254 as roots, but shoots have only $1.8 \times$ as much coenzyme Q as roots, indicating that Q254 is more concentrated in green tissues. In order to answer Question 3, we used variegated leaves of Pandanus vetchii from which alternating strips of white and green tissues were cut and assayed. The Q254 was $10 \times$ higher in the green tissue and Q275 was only $3 \times$ higher in the green part. It is apparent that some Q254 is in the plant tissue which does not have chlorophyll; it may be in proplastids where it may be involved in carotinoid synthesis (Norris et al. 1995). (The above studies were done between May 27 and July 17, 1958.)

Further definition of a role in photosynthesis would wait for study of PQ oxidoreduction function in chloroplasts since our focus in David Green's laboratory at the Enzyme Institute in Madison, Wisconsin, was a study of energy conversion in heart. Our first functional studies involved testing if Q254 acted like coenzyme Q in mitochondrial electron transport. In these extraction studies, we used

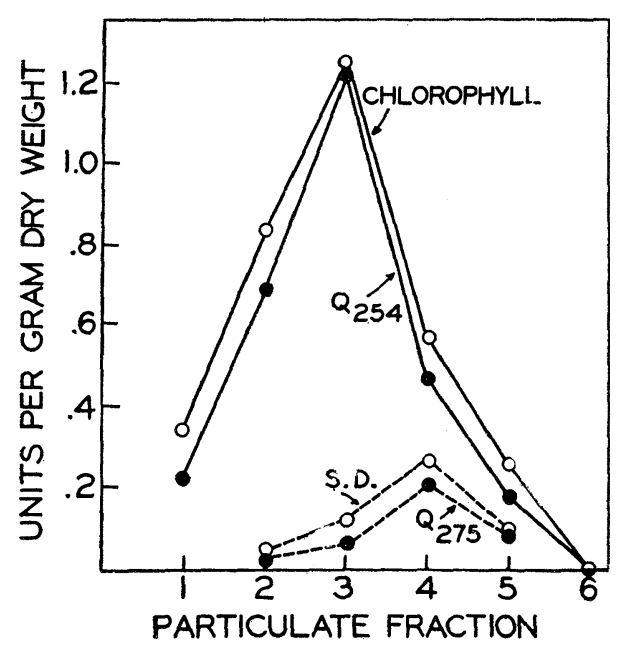

Fig. 3 Separation of membranes in a spinach leaf homogenate. Open circles (top curve) - chlorophyll absorption at $655 \mathrm{~nm} / \mathrm{mg}$ dry weight; solid circles (top curve) - plastoquinone (labeled as Q254), mg/g dry weight; solid circles (bottom curve)—coenzyme Q (labeled as Q275), $10 \mathrm{mg} / \mathrm{g}$ dry weight. Open circles (bottom curve)—succinic dehydrogenase (S.D.) mmole $\times 100 / \mathrm{min} \times \mathrm{mg}$ dry weight. This experiment indicated that Q254 could function in photosynthesis. (After Crane 1959a) isooctane as the solvent which was a mistake since we knew that it gave rather non-specific restoration of succinoxidase and induced a requirement for phospholipid and neutral lipids. After all, when Donaldson et al. (1958) reported tocopherol restoration of DPNH oxidase after isooctane extraction, I wrote to warn him that the effect was unspecific since beef serum albumin also worked. In the isooctane procedure, Q254 often gave some restoration of succinate oxidase. The complications of isooctane extraction are illustrated in Crane (1959b, 1960). We used isooctane because we could purchase a spectral pure grade chemical with no impurities to interfere with the UV spectrum. Amesz (1977) has discussed the problems involved with solvent extraction. After switching to acetone extraction in which Q254 did not replace coenzyme Q (Ambe and Crane 1960), we concluded that Q254 did not belong in the coenzyme Q group, contrary to our earlier conclusion (Crane 1959b).

To our delight, David Green was very tolerant of our further study of Q254 even after it was clear that it was not involved in mitochondrial energy coupling. One day I had a big separatory funnel full of spinach extract on my bench. David came in and said 'Oh! Cytochrome oxidase'. When I said 'no it is spinach lipids', he turned and stomped out. I think he was quite happy when Q254 fitted into the general concept of quinones in energy coupling.

Fortunately, studies of solvent extraction of chloroplasts were done with heptane or petroleum ether, and the readdition was mostly done by the evaporation technique. Lynch and French (1957) had earlier used this procedure to extract carotene which restored dye photoreduction when added back. Bishop (1958) took up this extraction approach and found that the extract restored activity but purified carotene was inactive. Instead, he found that Vitamins K3 and K5 were effective. Later examination of the extract showed that no Vitamin $\mathrm{K}$ was present even though biological assay showed as if Vitamin $\mathrm{K}$ was present. Instead of Vitamin K, Bishop (1959) found Q254 and showed that it restored activity. Later, Okayama and Butler (1972) showed, using hexane extraction, partial restoration by PQ and partial restoration by carotene. We found $50 \%$ restoration of ferricyanide and NADPH reduction with reduced PQ and less restoration with oxidized PQ (Wood and Crane 1965; Wood et al. 1966). Bishop's results (1959) with Vitamin K extraction and recovery are similar to Kofler's original search of trying to find Vitamin K1 and instead finding a quinone that he referred to as 'ein pflanzliches chinon' (Q254). Later Vitamin K1 was shown to be concentrated in the green parts of plants (Lichtenthaler 1962) and it was recovered from spinach chloroplasts in amounts sufficient to function in photosynthesis (Kegel and Crane 1962). In later studies, Lichtenthaler (1969) showed that Vitamin $\mathrm{K} 1$ is specifically bound to photosystem 1 
particles of chloroplasts suggesting a function in electron transport catalyzed by photosystem 1 . Biggins and Mathis (1988) showed its function in Photosystem I. Even the desmethyl Vitamin K, which we found while searching through chloroplast lipids (McKenna et al. 1964) turned out to be significant as a precursor to Vitamin K (Lohmann et al. 2006).

\section{The nomenclature and my becoming aware of the work of Kofler}

When Folkers came to Madison (Wisconsin) in 1957 to discuss collaboration in the study of Q275, he suggested that it should have a proper name. He favored calling it coenzyme Q since at that time there was no Vitamin Q and he was convinced that a compound with such an essential role in energy conversion would be found to be deficient in some condition and therefore be a Vitamin Q. Following his suggestion, we accepted the name coenzyme $\mathrm{Q}$ based on its function as a cofactor for succinoxidase (Green and Crane 1958). Since we did not know much about any function for Q254, we kept on referring to it by number until after January 1959. I had submitted a paper to Plant Physiology at that time, where I had compared the restoration of succinoxidase in isooctane extracted beef heart mitochondria by coenzyme Q from cauliflower with Q254, also from cauliflower. The reviewers approved the paper but Martin Gibbs, the editor of the journal, wrote that he didn't approve the designation of compounds by number so "Why don't you give it a name." Since we knew it was concentrated in plastids, I changed all the Q254 in the article to plastoquinone (Crane 1959b). In late 1958, before my submission of this article, someone had told me about the article by Kofler (1946) on a plant quinone, published in a Festschrift for Emil Christoph Barell, which had turned out to be identical to Q254. Fortunately, the Chemistry Library, at the University of Wisconsin, had a copy of the book. In the first papers by Kofler, the quinone was only referred to as eines pflanzlichen quinone. At the Ciba meeting, Isler et al. (1961) referred to it as koflerquinone. The only prior mention of this quinone I have found is on page 141 in a book on Naturally Occurring Quinones (Thomson 1957).

At the Ciba Symposium On Quinones in Electron Transport (Wolstenholme and O'Connor 1961), the question of names came up which led the IUPAC-IUB (International Union of Pure and Applied ChemistryInternational Union of Biochemistry) to appoint a committee to approve suitable names (see IUPAC-IUB Commission on Biochemical Nomenclature 1965); among the names used, the committee chose ubiquinone with a secondary choice of coenzyme Q. They selected plastoquinone over koflerquinone.
Advances in equipment and techniques were important factors in our discovery of coenzyme $Q$ and the rediscovery of PQ. In 1956, David Green's laboratory acquired a recording absorption spectrophotometer which made it possible to record the absorption spectrum from chromatography samples, just in minutes instead of the hours, as was done earlier when we were plotting the data point by point, obtained from a hand-operated machine. Chromatographic identification of the compounds was greatly improved by the development of greasy paper chromatography for separation of coenzyme Q analogs (Lester and Ramasarma 1959). An original chromatogram is seen in Fig. 4 (left panel). Even better resolution was achieved with thin layer chromatography on silica gel coated plates (Fig. 4, right panel; see Crane et al. 1966; Griffiths et al. 1966).

\section{Role of plastoquinone in photosynthesis}

The study of PQ function by solvent extraction and restoration has the disadvantage that the solvent may modify membranes or create artificial alternative electron transport systems. We measured the effect of light on the redox state of PQ in chloroplasts. We exposed chloroplasts to various intensity of tungsten light and extracted chloroplasts with acidified isooctane to decrease quinol reoxidation. Exposure to low light (600 foot-candles) caused as much as $80 \%$ reduction of the endogenous quinones when measured at $255 \mathrm{~nm}$ (Table 3). As a further assay, we measured reductant in the extract by the reduction of ferric ions (ferric chloride-dipyridyl). Clearly, PQ was available to electrons from illuminated chloroplasts (Crane et al. 1960). Redfearn and Friend (1961a, b) and Friend and Redfearn (1963) conducted a more extensive study in which they obtained only $15 \%$ reduction in light, compared to as much as $80 \%$ reduction in our study. The variation in the extent of reduction is not surprising in view of the fact that PQ functions between the two light reactions; it is reduced by Photosystem II (PS II) and oxidized by Photosystem I, PS I (see, e.g., Rabinowitch and Govindjee 1969, available free on the internet). Further, in mature leaves, part of the PQ can be in storage and, thus, not available for reduction.

Friend and Redfearn (1963) showed that DCMU (3-(3,4dichloro-phenyl)-1,1 dimethyl urea) and o-phenanthroline inhibited the reduction of PQ by Photosystem II (PS II) and that ammonia, which uncouples photophosphorylation, increases oxidation of PQ. Further, Friend and Redfearn (1963) proposed two functional sites for PQ, consistent with the conclusions of Trebst (1963) and Stiehl and Witt (1969; also see Witt 1971), where the primary site was for the transfer of electrons from PS II to PS I, and a secondary site was on PS I. Trebst (1963) showed that partial 


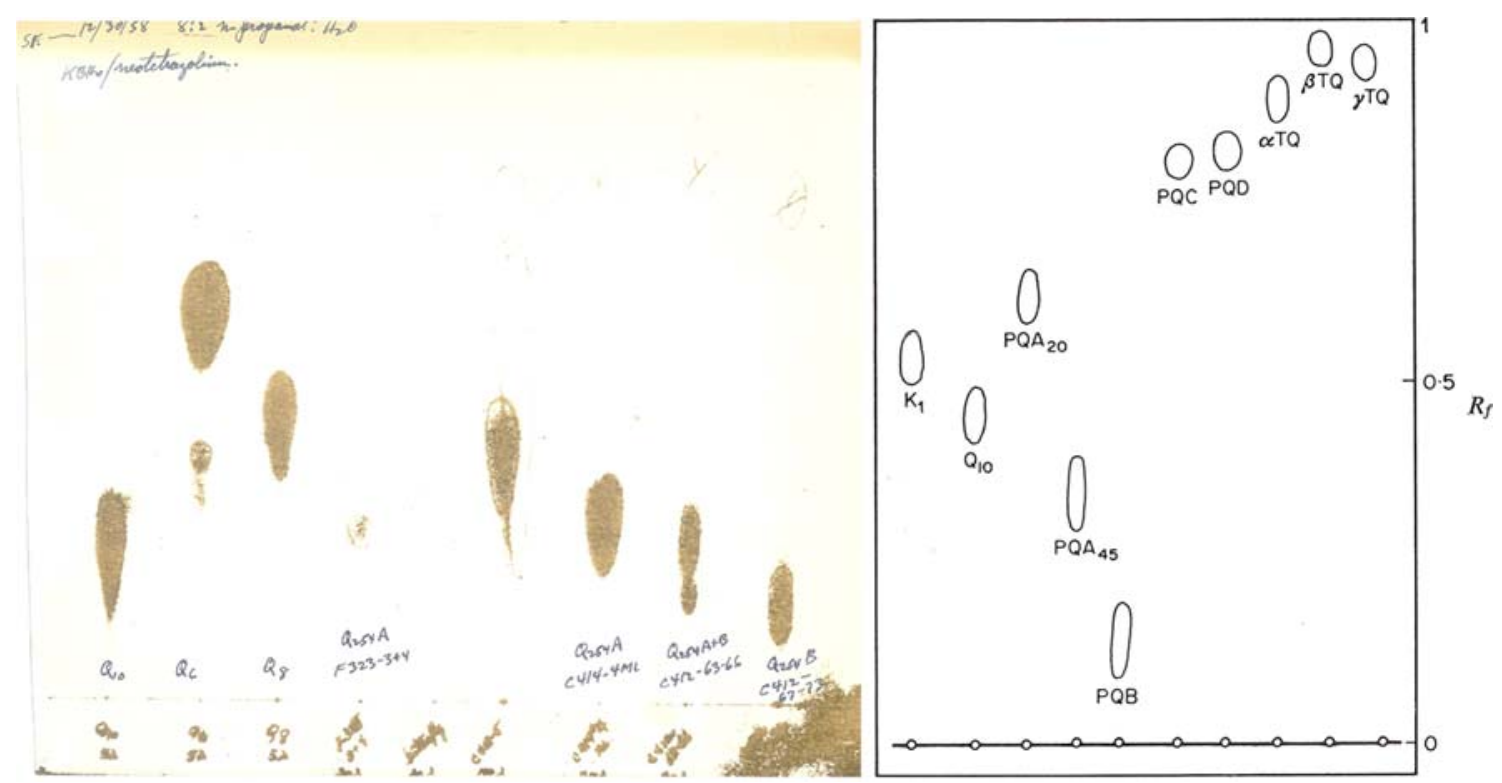

Fig. 4 Left panel An original chromatogram is shown here for historical reasons; for further information, write to the author. Right panel Chromatographic separation of lipophilic quinones on paraffin impregnated paper showing separation of plastoquinones $\mathrm{A}, \mathrm{B}$, and $\mathrm{C}$. Plastoquinone $\mathrm{D}$ is now considered as one of the plastoquinone $\mathrm{C}$ group. Other quinones shown are Q10 (coenzyme Q10). K1 (Vitamin K1), PQA20 (Plastoquinone homolog with 20 carbon prenyl side chain), $\alpha, \beta$, and $\gamma$ TQ (Tocopherylquinones). Developed in water:NN-dimethylformamide (2.5/97.5); detection of oxidized quinones was by leucomethylene blue. (After Crane et al. 1966)

Table 3 Changes in redox state of plastoquinone in chloroplasts

\begin{tabular}{llll}
\hline Time $(\mathrm{min})$ & Illumination & Mg oxidized PQ & Microequivalent reductant $^{\#}$ \\
\hline 0 & Dark & 0.042 & 0.0419 \\
15 & Light (2000fc) & 0.0412 & 0.0327 \\
15 & Dark & 0.011 & 0.0676 \\
15 & Light $(600 \mathrm{fc})^{*}$ & 0.031 & 0.026 \\
Increased reductant & & & \\
\hline
\end{tabular}

Redox changes in light (at $600 \mathrm{fc}$ ) gave further support to a role of plastoquinone in photosynthesis. The absence of effect at $2000 \mathrm{fc}$ was not explained at that time. Extraction was with acidified isooctane as described in Crane et al. (1960); $f c$ Foot candles; *Unpublished experiment of December 30, 1959; "Ferric chloride-dipyridyl was used to titrate total reductants in the lipid extract

extraction of PQ inhibited ferricyanide reduction (PS II) which was restored by PQ, whereas NADP reduction (PS I) was inhibited only after more complete extraction, which was restored by PQ addition. In a study of the specificity of the restoration by quinones, Trebst and Eck (1963) found that restoration of NADP reduction was specific for 2,3 dimethyl benzoquinone(s), with an isoprenoid side chain, whereas ferricyanide reduction was restored by many diand tri-methyl o-benzoquinones (Trebst and Eck 1963). We note that the heptane extraction, used in these studies to remove PQs, did not damage the membranes since photophosphorylation, which needs intact membranes, was restored by PQ after extraction of lyophilized chloroplasts (Krogmann 1961).

More convincing analysis of a role for PQ in photosynthesis came from spectrophotometric measurement of light effects in intact cells or chloroplasts. In a study of photoinduced UV spectral changes in the blue green alga (a cyanobacterium) Anacystis, Amesz (1964) obtained spectral changes consistent with its role as an electron carrier between PS II and PS I. A similar conclusion was reached later by Stiehl and Witt (1969) who used spinach chloroplasts and the green alga Chlorella. These results agree with the extraction-restoration work, discussed above. Light of $638 \mathrm{~nm}$ led to a decrease in absorbance at $254 \mathrm{~nm}$ and light at $720 \mathrm{~nm}$ increased absorbance at $254 \mathrm{~nm}$, consistent with a redox role for PQ between the two photosystems (Rumberg et al. 1965). Later Bohme and Cramer (1972) measured spectral changes at $254 \mathrm{~nm}$ and related their measurements to the formation of ATP during electron transport between PS II and PS I. A site for PQ action between the photosystems was also indicated by the 
destruction of PQ by UV irradiation at $254 \mathrm{~nm}$ (Trebst and Pistorious 1965). The UV inhibition of the Hill reaction was then shown by Lichtenthaler and Tevini (1969) to be best correlated with the loss of plastohydroquinone. Later studies indicated that the first reduction of a PQ is by one electron transfer with the primary formation of a quinone radical (Van Gorkom 1974). Photoreduction of PQ to the semiquinone at $-40^{\circ} \mathrm{C}$ indicated that it can act as the primary electron acceptor for PS II (Pulles et al. 1974).

The interpretation of PQ function was then further complicated by the discovery of a variety of PQ analogs. Some analogs had shorter isoprenoid chains as in the coenzyme $\mathrm{Q}$ group, whereas others have modification of the side chain. The coenzyme $Q$ quinones are found with isoprene side chains, which vary in length from 5 to 10 isoprene units (Lester and Crane 1959). On the other hand, only two examples of modified isoprenoid chain length have been reported for PQ: these are 3 isoprene and 4 isoprene units. PQ3 was isolated from spinach chloroplasts by Misiti et al. (1965), whereas PQ4, as well as dimers of PQ4 and PQ9, from horse chestnut leaves, were isolated by Eck and Trebst (1963). No further study of PQ3 has been reported. Barr et al. (1967a, b) found PQ4 only in Horse Chestnut chloroplasts at one tenth the amount of PQ9. In contrast to PQ9, no PQ4 was in osmiophilic globules.

The sites for PQ function in PSII have been established primarily by crystallography. The extensive literature on this study will not be reviewed here. Basically, two binding sites for some form of PQ have been identified near the cytoplasmic surface of the chloroplast. Electrons are transferred from a chlorophyll-pheophytin complex successively through the bound PQ which is released from its binding site when it is reduced and protonated to become $\mathrm{PQH}_{2}$ in the membrane. On the luminal side, the reduced $\mathrm{PQ}\left(\mathrm{PQH}_{2}\right)$ is then oxidized by a cytochrome b6f complex; electrons are transferred for NADP reduction through PS1, and protons are released that builds up a proton gradient that is used to drive ATP synthesis (see, e.g., Barber and Andersson 1994). Thus, PQ is essential for linking PS I and PS II and for ATP synthesis.

\section{Different plastoquinones including the story of the Christmas tree}

A different structural modification appeared in the PQs as compared to the coenzyme Q group. We discovered several new quinones which eluted in different fractions than plastoquinone A (PQA). We tested for quinones by measuring the change in absorbance produced by borohydride addition. One new benzoquinone eluted near PQ and another came off much later. We gave the original $P Q$ the name PQA, the one near it plastoquinone $\mathrm{B}$ (PQB), and the more polar one the name plastoquinone $\mathrm{C}$ (PQC) (Kegel et al. 1962). Even in 1958, we had evidence from coated paper chromatography for the presence of PQB (Fig. 4). When I moved to The University of Texas at Austin, I started to look for a good source of PQB in the middle of winter, the most green I could see was my Canadian Christmas tree (Abies, Balsam Fir). Actually, I may have known that Kofler (1946) in his survey had found that fir needles to be the best supply for PQA. The Balsam fir turned out to be a good supply of both PQA and PQB. When I reported that at the CIBA Symposium, Folkers, in his concluding remarks, congratulated me on my dedication to research since I cut up my Christmas tree to carry on my goals (Fig. 5).

In order to guard against artifacts, we used two extraction procedures: one was the direct extraction of spinach chloroplasts with propanol-heptane and the other was saponification. Both the procedures gave PQB and PQC, but the yield of PQB was greatly reduced in the saponification extract which is consistent with an ester in PQB. The discovery of three more PQ look alikes started us on studies of distribution and possible function in photosynthesis (Table 4; see Henninger and Crane 1963). The PQ story became more complex when thin layer chromatography was introduced (Dilley 1964). Further fractionation separated PQC into two fractions with identical spectra. We designated the slower one on thin layer silica gel plates as PQD (Fig. 4; see Henninger and Crane 1964). The presence of PQA, PQB, PQC, PQD, $\alpha$-Tocopherolquinone $(\alpha$-TQ) and Vitamin K1 was generally supported by others (Griffiths 1965; Das et al. 1967; Williams 1968) although PQD was difficult to find in some cases (Egger and Kleinig

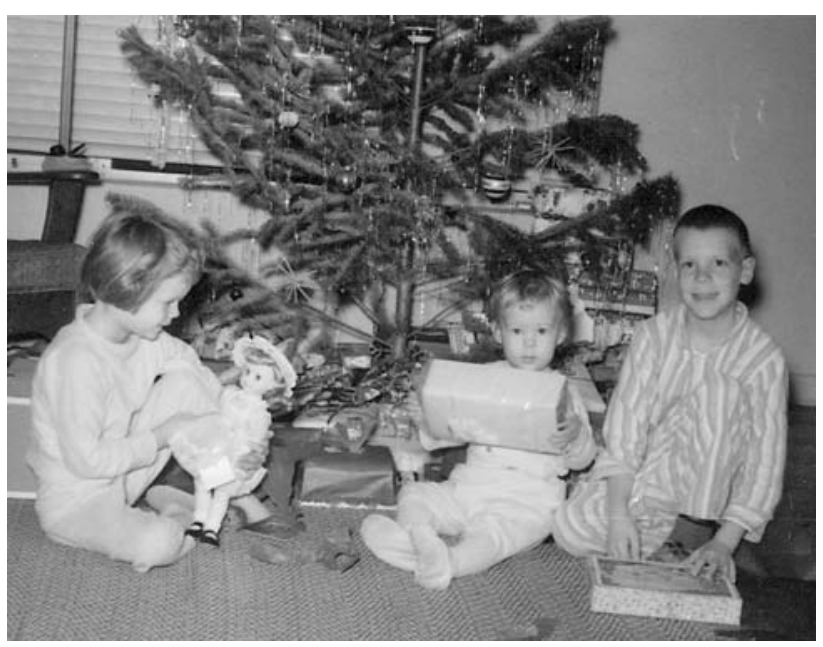

Fig. 5 The Crane kids opening presents under the fir Christmas tree in Texas which was cut up to make PQA and PQB the next day, using chloroform/isooctane 80/20. Photo, December 25, 1959 
Table 4 Quinones in spinach chloroplasts

\begin{tabular}{llc}
\hline Quinone & $\begin{array}{l}\text { Content } \\
\text { Micromoles of quinones/ } \\
\text { micromole Chlorophyll }\end{array}$ & $\begin{array}{c}\text { Ratio } \\
\text { Chlorophyll } \\
\text { to Quinone }\end{array}$ \\
\hline PQA & 0.10 & 10 \\
PQB & 0.005 & 200 \\
PQC & 0.025 & 40 \\
PQD & 0.009 & 100 \\
Vitamin K1 & 0.010 & 100 \\
$\alpha$-Tocopherylquinone & 0.010 & 100
\end{tabular}

Data from Crane and Henninger (1966) listing quinones in chloroplasts which are present in sufficient amount to be considered for a role in photosynthesis

1967). Booth (1962) used two-dimensional paper chromatography to show the presence of seven quinones in an extract of leaf lipids, three of which had PQ type spectra. The PQ story became more complex when thin layer chromatography was introduced. This technique was especially powerful when used in two dimensions. Using this procedure, Griffiths et al. (1966) separated PQB and PQC into six components each. They suggested that PQD was actually three units of PQC. They designated the new series as $\mathrm{PQB} 1, \mathrm{PQB} 2, \mathrm{PQB} 3, \mathrm{PQB} 4, \mathrm{PQB} 5, \mathrm{PQB} 6$ and $\mathrm{PQC} 1, \mathrm{PQC} 2, \mathrm{PQC} 3, \mathrm{PQC} 4, \mathrm{PQC5}$, and PQC6. The original $\mathrm{PQC}$ was found to contain $\mathrm{PQC} 1$ through $\mathrm{PQC} 4$ and the original PQD was PQC5 and PQC6 (see Barr et al. 1967a, b; Fig. 6).

Extensive study of the distribution of the 12 new isoprene analogs with modified side chains (Fig. 7) was done to see if any of them were available in amounts sufficient to play any role in photosynthesis. Lichtenthaler and Calvin (1964) found PQA in what was called "quantosomes" [this term has now been abandonedEditor] in the same ratio to chlorophyll as in whole chloroplasts which indicated they were available in the photosynthetic unit. In a personal communication, Calvin informed me that they found no coenzyme Q in chloroplasts. In 17 species, Rita Barr and I (see Barr and Crane 1967) found that PQA and PQC1-C4 were regularly present in significant amounts (over $0.004 \mathrm{M} \mathrm{PQ/}$ mg chlorophyll), whereas $\mathrm{PQB}$ and PQC5-PQC6 were often missing. The same pattern was found by Sun et al. (1968) in 21 species, ranging from cyanobacteria to red algae: PQA and PQC1-PQC4 were always present (except in a white strain of Euglena). Several studies have shown that PQA and PQC1-PQC5 increase as plants age (Lichtenthaler 1969). Likewise, an increase of PQA and PQC1-PQC4 occurs during greening of etiolated plants (Barr and Crane 1970). PQB did not appear
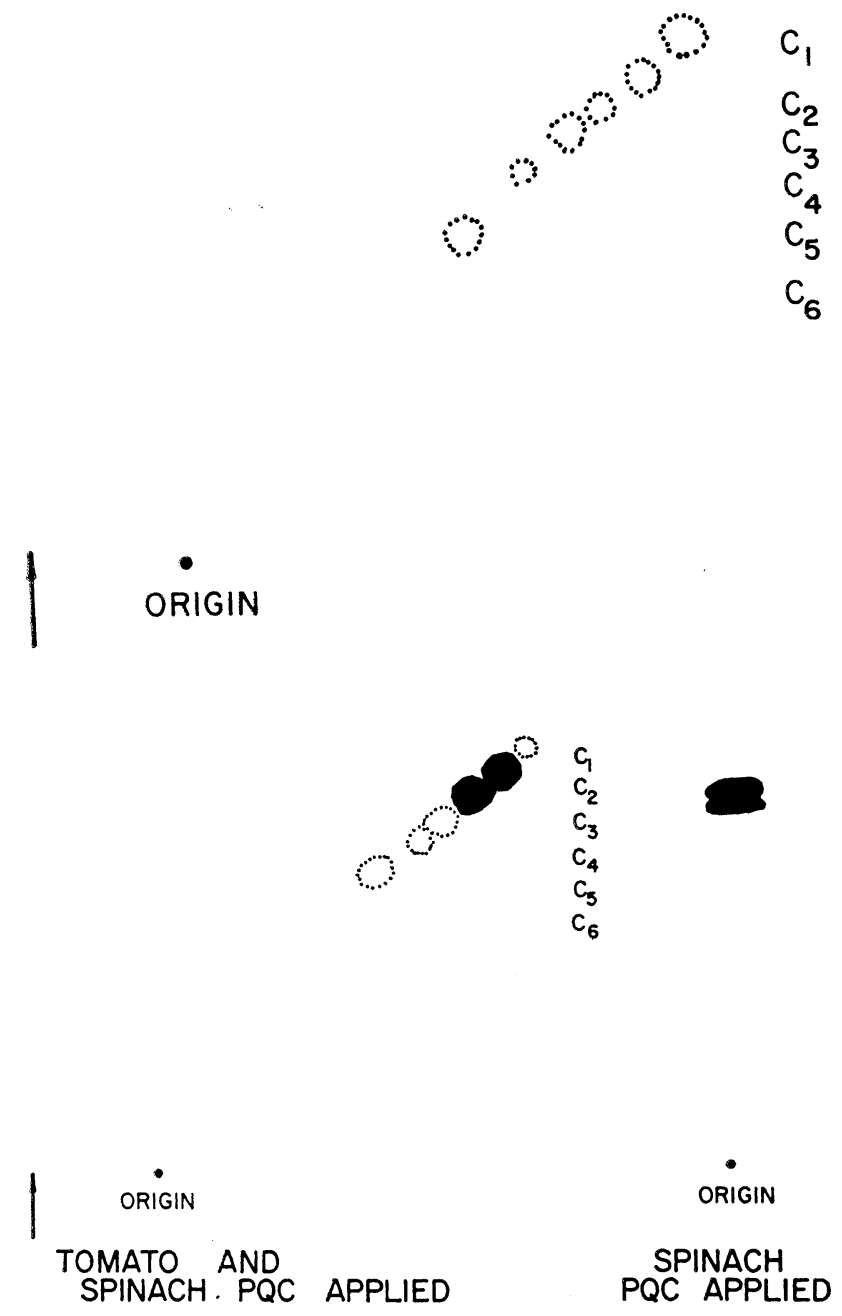

Fig. 6 Top Two-dimensional thin layer separation of six Plastoquinone $\mathrm{C}$ subunits, from tomato, in diisopropyl ether-benzene (15:85) in both directions. Bottom Cochromatography of tomato PQC with spinach PQC 2 and 3 in the same solvent. PQC2 and PQC3 are the major PQCs in spinach and they move with tomato PQC 2 and 3. (After Barr et al. 1967a, b)

even after $72 \mathrm{~h}$ of light and only in maize did PQC5PQC6 appear with short exposure to light (Barr and Crane 1970). The quinones that appear in the light are the most likely to be involved in photosynthesis; these include PQA, PQC1-PQC4, Vitamin K1, and $\alpha$-TQ. In a few plants, e.g., alfalfa, $\mathrm{PQC}$ is missing in winter (Bucke and Hallaway 1966). As pointed out by Amesz (1973), this precludes PQC from the main pathway of photosynthesis but does not eliminate it from its function in side reactions. The assay of PQC and $\alpha$-TQ is difficult because of incomplete extraction even with acetone which in contrast to PQA indicates tight bonding to some protein (Henninger and Crane 1963). Another problem with assay for PQC is that $10-30 \%$ may be in the reduced form (Kruk and Strzalka 1998). 
Fig. 7 Structure of plastoquinone A (top), plastoquinone $\mathrm{C} 1$ (middle), and plastoquinone B1 (bottom). Epoxidation of the double bond in the second prenyl group from the ring produces a hydroxyl group on the side chain to make PQC1. Successive oxidation of other prenyl groups makes PQC 2, 3, 4, 5, and 6. The PQB1, 2, 3, 4,5 , and 6 groups are produced by esterification of a fatty acid to the hydroxyl groups of the PQCs. The hydroxyl group makes the PQC more hydrophilic and could change its location in the membrane (Wallwork and Pennock 1968)

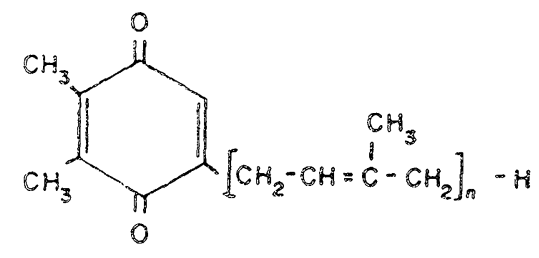

PLASTOQUINONE A $45 n=9$ PLASTOQUINONE A $20 \quad n=4$<smiles>CC1=CC(=O)C(C)=CC1=O</smiles>

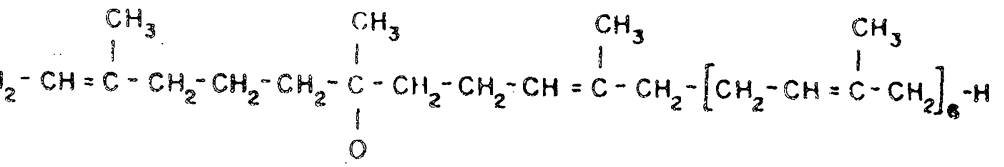

(1) $(4-9)$

PLASTOQUINONE $C_{\text {, }}$<smiles>[R]C(=O)OC(C)(CCCC(C)=CCC1=CC(=O)C(C)=C(C)C1=O)CC[Te]OON</smiles>

\section{The research group of Morton in Liverpool worked out the structure of $\mathrm{PQB}$ and $\mathrm{PQC}$}

The structure of the PQB and PQC groups appears to depend on epoxidation of the isoprene side chain. Oxidation of the double bonds in the side chain by $\mathrm{H}_{2} \mathrm{O}_{2}$ would produce the epoxide which would isomerize to a hydroxyl group. The first double bond is not attacked but hydroxylation at subsequent double bonds would produce hydroxyl groups along the isoprenoid chain accounting for the formation of the 1 through 6 series of PQC which are more hydrophilic than the original PQA (Fig. 7). PQB is formed by esterification of the hydroxyl groups corresponding to 1 through 6 PQB. Further epoxidation would produce multiple hydroxyl or esterified prenyl units which have been referred to as PQZs (Das et al. 1967; Wallwork and Pennock 1968). Dunphy (1971) proposed that the hydroxyl group is produced by photooxidation. The presence of an ester group in $\mathrm{PQB}$ is consistent with the loss of $\mathrm{PQB}$ when saponification is used during extraction For example, only $3 \%$ of $\mathrm{PQB}$ is recovered compared to $58 \%$ of $\mathrm{PQA}$ when saponification is used during extraction of PQs from spinach leaves (Kegel et al. 1962). This is in agreement with removal of a fatty acid from the hydroxyl group on PQC.
While Morton's group (see Morton 1959) in Liverpool (Wallwork and Pennock 1968) and Goodwins group in Aberystwyth (Threlfal et al. 1965) were working out the structure and biosynthesis of all the new PQs, we started to try and see which ones had a role in photosynthesis. In view of Bishop' s success (see Bishop 1959) with petroleum ether extraction and restoration with PQA, we tried heptane extraction to test for restoration by the new PQs (Henninger and Crane 1966). Heptane extraction removes, with increasing extraction time, both PQA and PQC with more extraction of PQA first. After $4 \mathrm{~h}$ of extraction, $90 \%$ of PQA is removed and $75 \%$ of PQC, with a $66 \%$ loss of indophenol photoreduction activity. Both PQA and PQC restore some activity and the combined quinones restore further activity. After heptane extraction of dry spinach chloroplasts, we obtained a slight restoration of indophenol and NADP reduction by PQA and PQC separately but almost complete restoration by the combination of the two quinones. The optimum amount of PQC was found to be one tenth of the amount of PQA (Henninger and Crane 1967). PQC has also been shown to restore oxygen production in petroleum ether extracted tobacco chloroplasts with the same efficiency as PQA. The response to DCMU is different for the two quinones. PQC shows a biphasic inhibition with a sudden transition to $50 \%$ inhibition at 
$0.25 \mathrm{M}$. With PQA, there is a steady slow decline without the sharp transition to $50 \%$ inhibition at $0.20 \mathrm{M}$ (Kruk et al. 1998).

\section{Further research provided new insights into the role of plastoquinones}

Trebst et al. (1963) used differential extraction with petroleum ether to define two different quinone sites. With mild extraction, ferricyanide reduction was decreased, but NADP reduction was not affected; whereas with exhaustive extraction, NADP reduction was also decreased. Since PQC is still bound after mild petroleum ether extraction, while PQA is mostly extracted, the results suggest that PQC is on a more specific path to NADP, whereas ferricyanide is on a path that requires PQA. A study of chlorophyll $a$ fluorescence response in chloroplasts after wet or dry heptane extraction of PQs indicated two sites for PQ function (R. Govindjee et al. 1970). Using the same preparations, Govindjee et al. (1970) showed that the absorption changes of the reaction center of PS II Chl $a$-II (now labeled as P680) was not due to Chl $a$ fluorescence artifact. Witt (1971) has summarized spectrophotometric evidence for the two sites involving PQ. Changes in PQ absorption at $265 \mathrm{~nm}$ in response to bicarbonate removal also indicates two sites for PQ function between photosystems, but does not identify which PQs are involved (Siggel et al. 1977; for a review on the role of bicarbonate in the $\mathrm{PQ}$ region, see Van Rensen et al. 1999).

Extraction of mitochondria by acetone, to remove quinones, showed a specific requirement for coenzyme $Q$ (Ambe and Crane 1960). In chloroplasts, Henninger and Crane (1963) found that acetone extraction removed all of the PQA and PQB, but left $50 \%$ of the PQC and PQD; this difference implies a tight binding site for PQC. Acetone extraction also removed $80 \%$ of the chlorophyll which makes restoration studies of doubtful significance.

Tevini and Lichtenthaler (1970) showed that most of the PQs were in the PS II particles, whereas Vitamin K1 was in the PS I fraction, as measured after removal of the osmiophillic lipid globules. Thus far, the presence of only PQA, in what Lichtenthaler calls plastoglobuli, has been studied. Lichtenthaler and Peveling (1967) have proposed that the globuli in leucoplasts may act as storage sites for lipoquinones for supply to developing plastids. Under high light, the globuli continue to enlarge and accumulate PQ which is in the reduced form. Ytterberg et al. (2006) have shown that these globules contain enzymes involved in PQ synthesis, as well as kinases, which may control PQ synthesis. The hydroquinone is synthesized in globules and is oxidized to quinone when it is transferred to the thylakoid (Lichtenthaler 1977, 2007). In mature leaves from three species, Lichtenthaler and Sprey (1966) found higher amounts of PQ and tocopherylquinone in globules. There was 10-40 times as much PQ in globules than in the

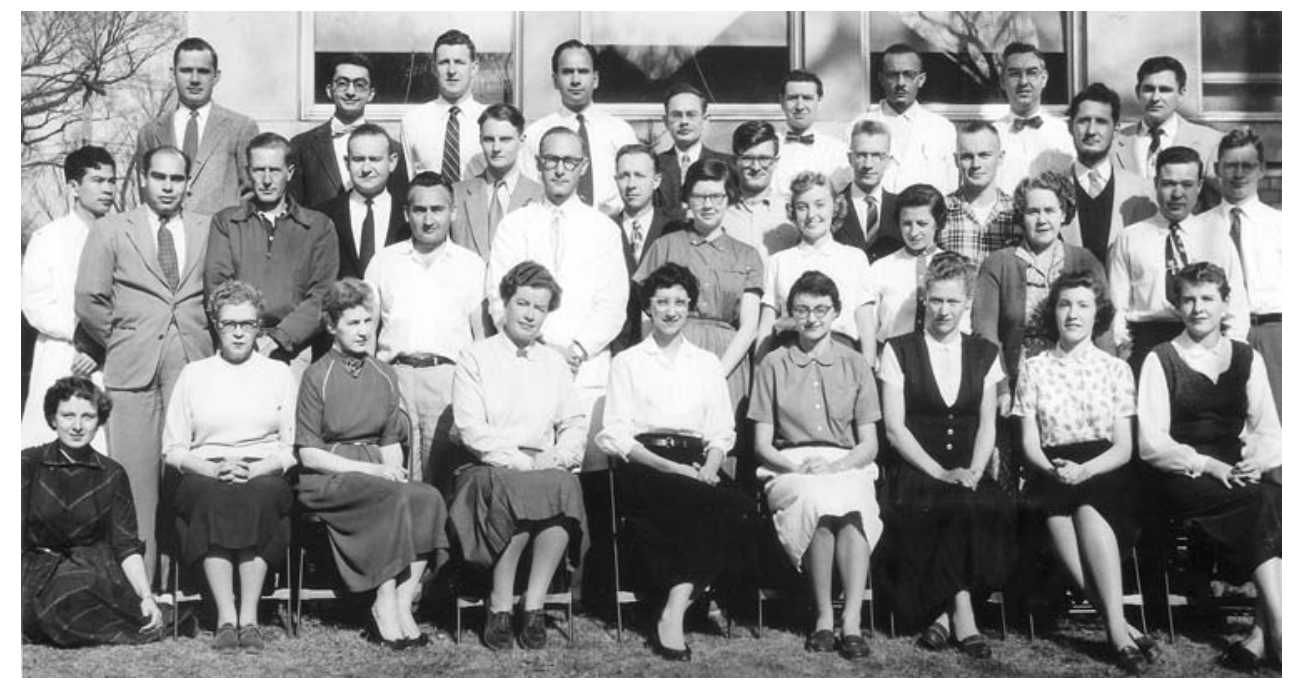

Fig. 8 The staff of David Green's section of the Enzyme Institute in 1956. In this group, Fred Crane and others [Wanda Fechner, Bob Lester, Carl Widmer, Kishore Ambe, and T. Ramasarma (the latter two are not in the picture)] started work on quinones. Back row (left to right) Dave Gibson, Joe Hatefi, Tony Linnane, Dexter Goldman, Nat Penn, Bruce Mackler, Howard Tisdale, Al Heindel, and Dan Zieglar. Second row (left to right) Seishi Kuwahara, Salih Wakil,
Helmut Beinert, Bob Lester, Alton Frost, Johan Jarnefelt, David Green, John Porter, Elizabeth Welch, unidentified, Wanda Fechner, Bob Basford, unidentified, Fred Crane, Sedate Holland, Carl Widmer, Robert Labbe, and Edward Titchne. Front row Ruth Reitan, Amine Kalhagen, Cleo Whitcher, Elizabeth Steyn-Parve, Jean Karr, Joanne Gilbert, Mildred Van der Bogart, Mary Benowitz, and Irene Wiersma. Photo, 1956 


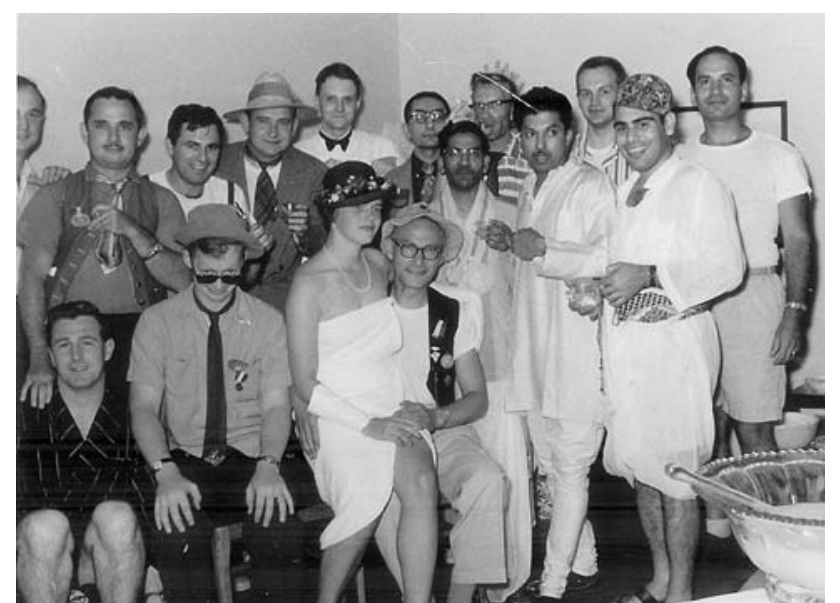

Fig. 9 A "Fancy dress" party of David Green's research group at the Enzyme Institute in Wisconsin. Back row (left to right) (half) Dave Griffiths, David (Dave) Gibson, Dan Ziegler, Robert (Bob) Lester, Johan Jarnefelt, Youssef (Joe) Hatefi, Robert (Bob) Basford, Frederick (Fred)Crane, Dexter Goldman. Front row (from left to right) Anthony (Tony) Linnane, Brad Tichner, Christina Jarnefelt, David Green, Ramasarma, Kishore Ambe, Salih Wakil. Photo and legend provided by Johan and Christina Jarnefelt. Photo, 1958

chloroplasts. The surprise is that globuli are sites of synthesis instead of being 'garbage bags' (Austin et al. 2006). In order to resolve the question of the function of the different PQs, biophysical study of quinone redox changes would be an ideal approach except for the fact that PQA,
$\mathrm{PQB}$, and $\mathrm{PQC}$ have identical absorption spectra. The other alternative is to find mutants and to discover if the formation of the epoxide derived quinones is under specific genetic control. Smillie and Levine (1962) have described mutants of Chlamydomonas with decreased PQ. Mutants ac-115 and ac-141 have one-fifth as much PQ as wild type. In these mutants, PS II is blocked; the nature of the remaining PQ is not known. Mutants for the PQ-binding protein in PS II are known and recognized as also acting as the binding site for several herbicides. Which type of PQ can bind at these sites is unknown (see, e.g., Erickson et al. 1989).

\section{Concluding remarks}

The most important result of my rediscovery of PQ was the identification of a quinone as an electron carrier between Photosystem II and Photosystem I in photosynthesis (Bohme et al. 1971; see Wydrzynski and Satoh (2005) for the details of PS II; and Golbeck (2006) for the details of PS I). As the hydroquinone can carry protons across the thylakoid membrane, it provides a mechanism for the generation of a proton gradient to drive ATP formation. Our discovery (or rediscovery) came at a fortunate time since a similar quinone, coenzyme $\mathrm{Q}$, had just been found to function in mitochondrial electron transport. The presence of $\mathrm{PQ}$ in green plant chloroplasts focused attention on

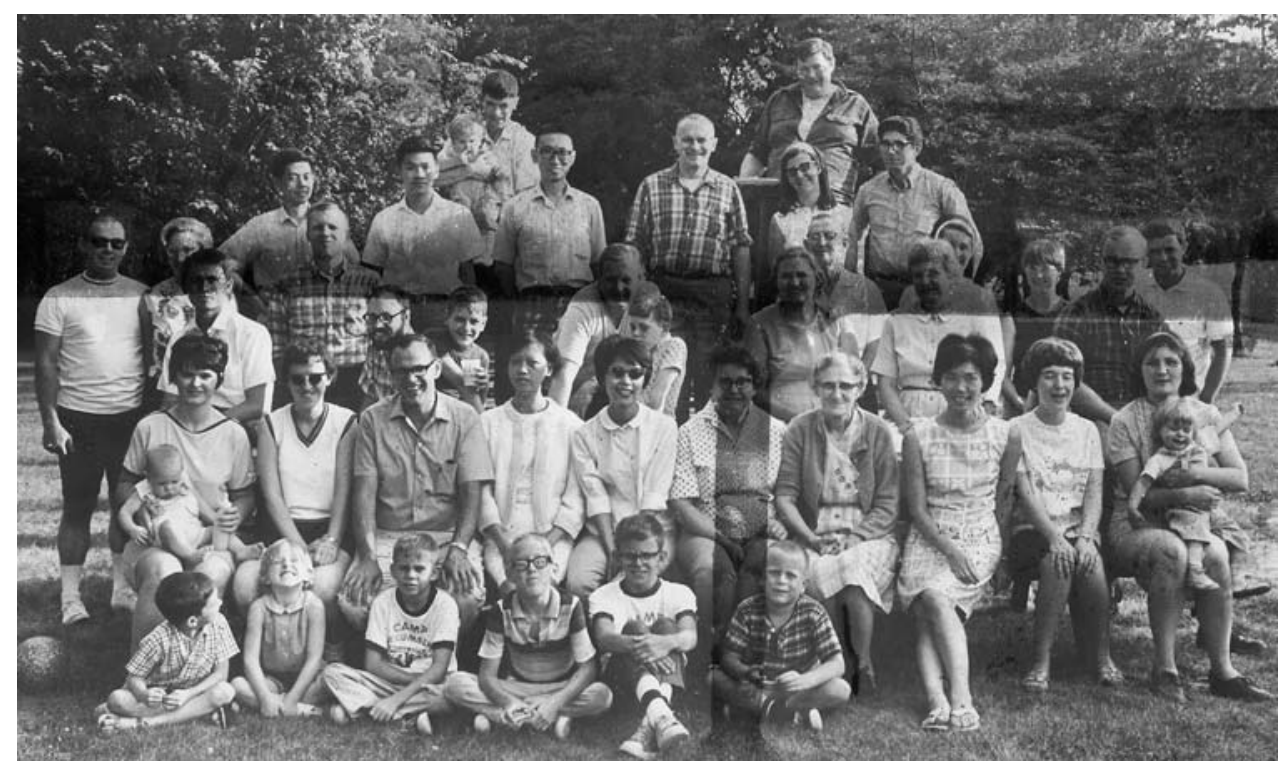

Fig. 10 Fred Crane's research group picnic. Although this photograph was damaged, it is shown here for historical purposes. Sitting on the ground: children at the picnic. First standing row 3rd from right is Helen Crane; 5th from right is Rita Barr. On the next standing row (just below the very top row), Ron Berezney (wearing glasses) is on the extreme right; 2 nd from right is Linda Funk; 3rd from right is the author Fred Crane (wearing checkered shirt); 4th from right is Frank Sun (wearing glasses). On the very top row is Jack Wilson (right above Linda Funk). All others in the photograph are either members of Crane laboratory or those related to these members. Photo, 1967 
its role in photosynthesis. Restoration by PQ of chloroplast electron transport after lipid extraction supported such a role. Further support came from biophysical and genetic analysis. Evidence for quinones in the energy conversion systems of plants, animals, and microbes made the general concept of proton driven energy conversion possible (Wolstenholm and O'Connor 1961). The identification of the PQ binding site as also a site for herbicide action is of practical benefit for herbicide design (Erickson et al. 1989). The discovery of PQB and PQC introduced new problems. Are they waste products from oxidative damage to PQ or do they have other functions? Similar compounds have been related to coenzyme Q in mitochondria (Friis et al. 1967; Sottocasa and Crane 1965) so they may be a product of random oxidative attack on prenyl side chains.

PQC is found in amounts similar to Vitamin K1 and $\alpha$ tocopherol quinone, all of which are found at $1 \mathrm{~mol}$ per $100 \mathrm{~mol}$ chlorophyll (Table 4). Since that amount is enough for Vitamin K to function in PS I (Biggins and Mathis 1988; Snyder et al. 1991), PQC and $\alpha$-TQ are not excluded from a redox role in the chloroplast on the basis of insufficient amount. PQA is found at 10-20 times the concentration of PQC; so, there is enough for other functions (Egger 1965). One of the other functions appears to be redox control as in control of antenna chlorophyll (Allen 2002; Frigerio et al. 2007). Functions of PQ in electron pathways other than photosynthesis have also appeared as in NADH oxidation and carotene synthesis (Norris et al. 1995; Guera et al. 2005). It is also possible to consider if PQC might act as an uncoupler of photophosphorylation. Since coenzyme $\mathrm{Q}$ is a cofactor for the uncoupling protein in animal mitochondria, the change in lipophilicity from the hydroxyl group on PQC might change its migration through the membrane, thus affecting proton transfer. The opposing roles as oxygen radical producer or scavenger should also be considered for PQ. Reduced PQ has been shown to protect against radical formation at high light intensity (Hundal et al. 1995). The discovery of PQ led to the dentification of $\alpha, \beta$ and $\gamma$, tocopherols, and tocopherylquinones in chloroplasts with possible significance to radical control (Dilley and Crane 1963). The control of cholesterol and coenzyme Q synthesis by epoxy coenzyme $\mathrm{Q}$ opens up new possible roles for PQC (Bentinger et al. 2008). The presence of PQ and tocopherylquinone in the chloroplast envelope (Lichtenthaler et al. 1981) is evidence for a site for synthesis or may indicate alternate redox systems dependent on PQ. PQ is not exclusively in chloroplasts but some appears to be present in roots and nongreen tissues. In animals, coenzyme $\mathrm{Q}$ has functions in membranes other than mitochondria. It is involved as an antioxidant and in proton transfer in Golgi vesicles (Barr et al. 1984), lysosomes (Gille and Nohl 2000), and plasma membrane (Sun et al. 1992). Thus, investigation of PQ

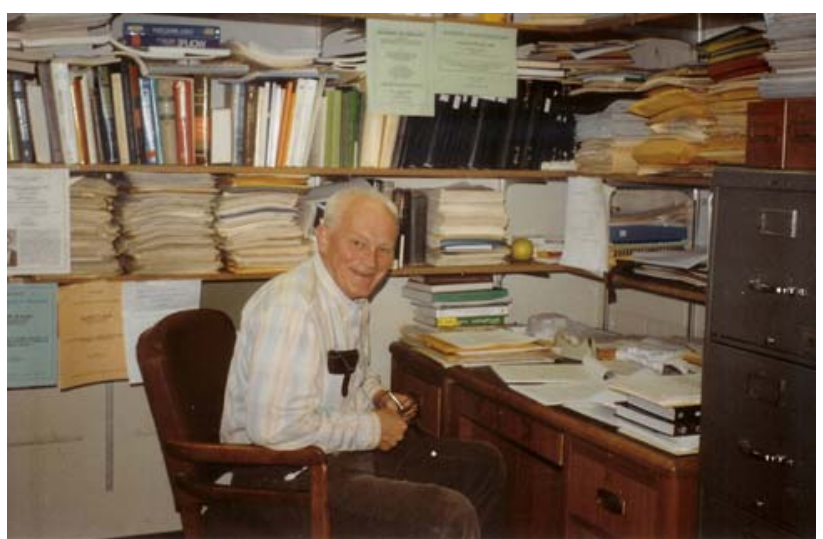

Fig. 11 Fred L. Crane (the author) in his office at Purdue University. Photo, 1972

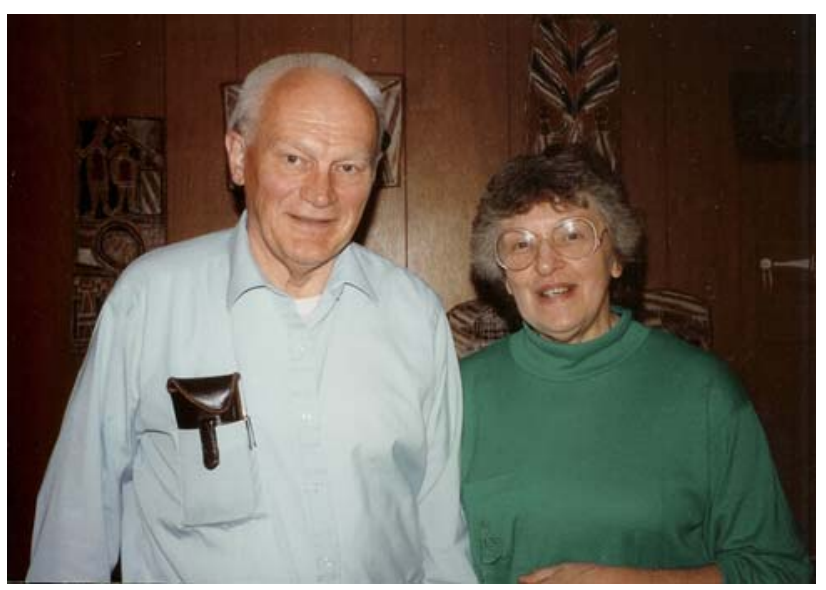

Fig. 12 Fred and Marilyn Crane at Purdue University (Marilyn was in the Vision Research Group). Photo, 1983

needs a broad scope and further definition of function for its analogs.

At the suggestion of Govindjee, I have included here five photographs: Fig. 8 is a 1956 group photograph of David Green's laboratory staff where I, with others, rediscovered PQs and Fig. 9 shows a photograph of a "Fancy dress" party of Green's group in 1958. Figure 10 is a 1967 group photograph of my research group at a picnic near Purdue University, whereas Fig. 11 is my photograph in my office at Purdue University, taken in 1972. Finally, Fig. 12 shows my photograph with my wife Marilyn, taken in 1983.

Acknowledgments David Green (of the Enzyme Institute, University of Wisconsin, Madison) deserves a lot of credit for encouraging my research into PQ when it was not in the mainstream of heart bioenergetics that he was interested in. Further, Karl Folkers deserves credit for interrupting coenzyme $\mathrm{Q}$ research to provide analogs of PQ that advanced research in this area. I express my appreciation to my dedicated colleagues who worked on the PQ story with me: Rita Barr, 
Larry Kegel, Barbara Ehrlich, Pat Wood, Melva Henninger and H. N. Bhagavan. I thank Govindjee, the founding Historical Corner editor of Photosynthesis Research, for inviting me to write this personal minireview, for constant interaction, suggestions and editing from its original draft to the final manuscript. I thank Lilli A Davis for her technical assistance with the manuscript.

\section{References}

Allen JF (2002) Plastoquinone redox control of chloroplast thylakoid protein phosphorylation and distribution of excitation energy between photosystems: discovery, background, implications. Photosynth Res 73:139-148

Ambe KS, Crane FL (1960) Studies on the electron transport system. XXVI. Specificity of coenzyme Q and coenzyme Q derivatives. Biochim Biophys Acta 43:30-40

Amesz J (1964) Spectrophotometric evidence for the participation of a quinone in photosynthesis of intact blue-green algae. Biochim Biophys Acta 79:257-265

Amesz J (1973) The function of plastoquinone in photosynthetic electron transport. Biochim Biophys Acta 301:35-51

Amesz J (1977) Plastoquinone. In: Trebst A, Avron M (eds) Encyclopedia of plant physiology, vol 5. Springer, Berlin, pp 238-246

Austin JR, Frost E, Vidi PA, Kessler F, Staehelin LA (2006) Plastoglobules are lipoprotein subcompartments of the chloroplast that are permanently coupled to the thylakoid membrane and contain biosynthetic enzymes. Plant Cell 18:1693-1703

Barber J, Andersson B (1994) Revealing the blueprint of photosynthesis. Nature 370:31-34

Barr R, Crane FL (1967) Comparative studies on plastoquinones. III. Distribution of plastoquinones in higher plants. Plant Physiol 42:1255-1263

Barr R, Crane FL (1970) Comparative studies on plastoquinones. V. Changes in lipophilic chloroplast quinones during development. Plant Physiol 45:53-55

Barr R, Magree L, Crane FL (1967a) Quinone distribution in horsechestnut chloroplasts globules and lamellae. Am J Botany 54:365-374

Barr R, Henninger MD, Crane FL (1967b) Comparative studies on plastoquinone II. Analysis for plastoquinones A, B, C, D. Plant Physiol 42:1246-1254

Barr R, Safranski K, Sun IL, Crane FL, Morre DJ (1984) An electrogenic pump associated with the Golgi apparatus of mouse liver driven by NADH and ATP. J Biol Chem 259:14064-14067

Bentinger M, Tekle M, Brismar K, Chojnacki T, Swiezewska E, Dallner G (2008) Polyisoprenoid epoxides stimulate the biosynthesis of coenzyme Q and inhibit cholesterol synthesis. J Biol Chem 283:14645-14653

Biggins J, Mathis P (1988) Functional role of vitamin K1 in photosystem 1 of the cyanobacterium Synechocystis 6803. Biochemistry 27:1494-1500

Bishop NI (1958) Vitamin K, an essential factor for the photochemical activity of isolated chloroplasts. Proc Natl Acad Sci USA 44:501-504

Bishop NI (1959) The reactivity of a naturally occurring quinone (Q255) in photochemical reactions of isolated chloroplasts. Proc Natl Acad Sci USA 45:1696-1702

Bohme H, Cramer WA (1972) Localization of a site of energy coupling between plastoquinone and cytochrome $\mathrm{f}$ in the electron transport chain of spinach chloroplasts. Biochemistry 11:1155-1160

Bohme H, Reimer S, Trebst A (1971) The effect of dibromthymoquinone, an antagonist of plastoquinone on non cyclic and cyclic electron flow systems in isolated chloroplasts. Z Naturforsch 26b:341-352

Booth VH (1962) A method for separating lipid components of leaves. Biochem J 84:444-448

Bucke C, Hallaway M (1966) The distribution of plastoquinone C and the seasonal variation in its level in young leaves of Vicia faba L. In: Goodwin TW (ed) Biochemistry of chloroplasts, vol 1. Academic Press, London, pp 153-157

Crane FL (1959a) Internal distribution of coenzyme Q in higher plants. Plant Physiol 34:128-131

Crane FL (1959b) Isolation of two quinones with coenzyme Q activity from alfalfa. Plant Physiol 34:546-551

Crane FL (1960) Quinones in electron transport. Coenzymatic activity of plastoquinone, coenzyme $\mathrm{Q}$ and related quinones. Arch Biochem Biophys 87:198-202

Crane FL (1961) Isolation and characterization of the coenzyme Q group and plastoquinone. In: Wolstenholme GEW, O'Connor $\mathrm{CM}$ (eds) Quinones in electron transport. Churchill, London, pp $36-75$

Crane FL, Dilley RA (1963) Determination of coenzyme Q (ubiquinone). Methods Biochem Anal 11:279-306

Crane FL, Henninger MD (1966) Function of quinones in photosynthesis. Vitam Horm 24:489-517

Crane FL, Hatefi Y, Lester RL, Widmer C (1957) Isolation of a quinone from beef heart mitochondria. Biochim Biophys Acta 25:220-221

Crane FL, Ehrlich B, Kegel LP (1960) Plastoquinone reduction in illuminated chloroplasts. Biochem Biophys Res Commun 3:3740

Crane FL, Henninger MD, Wood PM, Barr R (1966) Quinones in chloroplasts. In: Goodwin TW (ed) Biochemistry of chloroplasts. Academic Press, London, pp 133-151

Craven R (1931) A sensitive color reaction for certain quinones. J Chem Soc 1931:1605-1606

Das BC, Lounasmaa M, Tendille M, Lederer E (1967) The structure of the plastoquinones B and C. Biochem Biophys Res Commun 26:211-215

Dilley RA (1964) Thin layer chromatography of naturally occurring quinones and hydroquinones. Anal Biochem 7:240-246

Dilley RA, Crane FL (1963) Light-induced changes of $\alpha$-tocopherylquinone in spinach chloroplasts. Biochim Biophys Acta $75: 142-143$

Donaldson KO, Nason A, Garrett RH (1958) A requirement for alpha tocopherol in mitochondria DPNH oxidase. J Biol Chem 233:566-570

Dunphy PJ (1971) Phootosensitised oxidation of terpenes and its biological consequences. Chem Indust 1971:731-732

Eck VH, Trebst A (1963) Uber die Konstitution eines weiteren Plastochinons und seines dimeren aus Kastanienblattern. Z Naturforsch 18b:446-451

Egger K (1965) Die verbreitung von vitamin K1 und Plastochinone in Pflanzen. Planta 64:41-61

Egger K, Kleinig H (1967) Die plastochinonanalogen-ein kritischer vergleich. Zeit Pflanzenphysiol 56:113-121

Erickson JM, Pfister K, Rahirer M, Togasaki RK, Mets L, Rochaix JD (1989) Molecular and biophysical analysis of herbicide resistant mutants of Chlamydomonas reinhardtii. Plant Cell 1:361-371

Folkers K, Shunk CH, Linn BO, Trenner NR, Wolf DE, Hoffman CH, Page AC, Koniuszy FR (1961) Coenzyme Q. XXIII. Organic and biological studies. In: Wolstenholme GEW, O'Connor CM (eds) Quinones in electron transport. Churchill, London, pp 100-126

Friend J, Redfearn ER (1963) Studies of plastoquinone-2. Oxidationreduction reactions of plastoquinone in isolated chloroplasts. Phytochemistry 2:397-405

Frigerio S, Campoli C, Zorzan S, Fantoni LI, Crosetti C, Drepper F, Haehnel W, Cativelli L, Morosinotto T, Bassi R (2007) 
Photosynthetic antenna size in higher plants is controlled by the plastoquinone redox state at the post transcriptional rather than transcriptional level. J Biol Chem 282:29457-29469

Friis P, Daves GD, Folkers K (1967) New epoxy ubiquinones. Biochemistry 6:3618-3624

Gille L, Nohl H (2000) The existence of a lysosomal redox chain and the role of ubiquinone. Arch Biochem Biophys 375:347-354

Golbeck JH (ed) (2006) Photosystem I: the light-driven plasocyanin:ferredoxin oxidoreductase. In: Govindjee (Series Editor) Advances in photosynthesis and respiration, vol 24. Springer, Dordrecht

Govindjee, Döring G, Govindjee R (1970) The active chlorophyll a II in suspensions of lyophilized and tris-washed chloroplasts. Biochim Biophys Acta 205:303-306

Govindjee R, Govindjee, Lavorel J, Briantais J-M (1970) Fluorescence characteristics of lyophilized maize chloroplasts suspended in buffer. Biochim Biophys Acta 205:361-370

Green DE, Crane FL (1958) Structure of the mitochondrial electron transport system. In: International symposium on enzyme chemistry, Maruzen, Tokyo, pp 275-286

Griffiths WT, Wallwork JC, Pennock JF (1966) Presence of a series of plastoquinones in plants. Nature 211:1037-1039

Guera A, Calatayud A, Sabater B, Barreno E (2005) Involvement of the thylakoidal NADH-plastoquinone-oxidoreductase complex in the early responses to ozone exposure of barley seedlings. J Exp Bot 5(6):205-218

Hatefi Y, Lester RL, Crane FL, Widmer C (1959) Studies on the electron transport system. XVI. Enzymic oxidoreduction reactions of coenzyme Q. Biochim Biophys Acta 31:490-501

Henninger MD, Crane FL (1963) Restoration of photoreductase activities in acetone-extracted chloroplasts by plastoquinones and tocopherylquinones. Biochemistry 2:1168-1171

Henninger MD, Crane FL (1964) Isolation of plastoquinones C and D from spinach chloroplasts. Plant Physiol 39:598-602

Henninger MD, Crane FL (1966) Electron transport in chloroplasts 1. A combined requirement for plastoquinones $\mathrm{A}$ and $\mathrm{C}$ for photoreductionof 2,6 dichloroindophenol. J Biol Chem 241:5190-5196

Henninger MD, Crane FL (1967) Electron transport in chloroplasts. III. The role of plastoquinone C. J Biol Chem 242:1155-1159

Hundal T, Forsmark-Andree P, Ernster L, Andersson B (1995) Antioxidant activity of reduced plastoquinone in chloroplast thylakoid membranes. Arch Biochem Biophys 324:117-122

Isler O, Ruegg R, Langemann A, Schudel P, Ryser G, Wursch J (1961) Chemistry of ubiquinone and related compounds. In: Wolstenholm GEW, O'Connor C (eds) Quinones in electron transport. Churchill, London, pp 79-96

IUPAC-IUB Commission on Biochemical Nomenclature (1965) Nomenclature of quinones with isoprenoid side chains. Biochim Biophys Acta 107:5-10

Kegel P, Crane FL (1962) Vitamin K1 in chloroplasts. Nature 194:1282

Kegel P, Henninger MD, Crane FL (1962) Two new quinones from chloroplasts. Biochem Biophys Res Commun 8:294-298

Kofler M (1946) Ueber ein pflanzliches Chinon. In: Festschrift Emil Christoph Barell. Hoffmann Laroche, Basel, pp 199-212

Kofler M, Langemann A, Ruegg R, Chopard-dit-Jean LH, Rayroud A, Isler O (1959) Die Struktur eines pflanzlichen Chinons mit isoprenoider Seitenkette. Helvetica Chem Acta 42:1283-1292

Krogmann DW (1961) A requirement for plastoquinone in photosynthetic phosphorylation. Biochem Biophys Res Commun 4:275277

Kruk J, Strzalka K (1998) Identification of plastoquinone C in spinach and maple leaves by reverse phase high performance liquid chromatography. Phytochemistry 49:2267-2271
Kruk J, Burda K, Schmid GH, Radunz A, Strzalka K (1998) Function of plastoquinones $\mathrm{B}$ and $\mathrm{C}$ as electron acceptors in photosystem 2 and fatty acid analysis of plastoquinone B. Photosynth Res 58:203-209

Lester RL, Crane FL (1959) The natural occurrence of coenzyme Q and related compounds. J Biol Chem 234:2169-2175

Lester RL, Ramasarma T (1959) Chromatography of the coenzyme Q family of compounds on silicone impregnated paper. J Biol Chem 234:672-676

Lichtenthaler HK (1962) Vergleichende Bestimmungen der VitaminK1-Gehalte in Blattern. Planta 67:731-753

Lichtenthaler HK (1969) Die Bildung uberschussiger Plastidenchinone in den Blattern von Ficus elastic Roxb. Z Naturforsch 24b:1461-1466

Lichtenthaler HK (1977) Regulation of prenylquinone synthesis in higher plants. In: Tevini M, Lichtenthaler HK (eds) Lipids and lipid polymers in higher plants. Springer, Berlin, pp 231-258

Lichtenthaler HK (2007) Biosynthesis, accumulation and emission of carotenoids, $\alpha$-tocopherol, plastoquinone, and isoprene in leaves under high photosynthetic irradiance. Photosynth Res 92:163179

Lichtenthaler HK, Calvin M (1964) Quinone and pigment composition of chloroplasts and quantasome aggregates from Spinacia oleracea. Biochim Biophys Acta 79:30-40

Lichtenthaler HK, Peveling E (1967) Plastoglobuli in verschiedenen differenzierungstadien der Plastiden bei Allium cepa L. Planta 72:1-13

Lichtenthaler HK, Sprey B (1966) Uber die osmiophilen globularen Lipideinschlusse der Chloroplasten. Z Naturforsch 21b:690-697

Lichtenthaler HK, Tevini M (1969) Die Wirkung von UV-Strahlen auf die Lipochinon-Pigment-Zusammensetzung isolierter Spinatchloroplasten. Zeit Naturforsch 24b:764-769

Lichtenthaler HK, Prenzel U, Douce R, Joyard J (1981) Localization of prenylquinones in the envelope of spinach chloroplasts. Biochim Biophys Acta 641:99-105

Lohmann A, Shottler MA, Kessler F, Brehelin C, Bock R, Cahoon EB, Dormann P (2006) Deficiency in phylloquinone (vitamin K): methylation affects prenyl quinone distribution, photosystem 1 abundance and anthocyanin accumulation in the Arabidopsis Atmen G mutant. J Biol Chem 281:40461-40472

Lynch VH, French CS (1957) Carotene an active component of chloroplasts. Arch Biochem Biophys 70:382-391

McKenna M, Henninger MD, Crane FL (1964) A second napthoquinone in spinach chloroplasts. Nature 203:524-525

Misiti D, Moore HW, Folkers K (1965) Identification of plastoquinone 3 from chloroplasts. J Am Chem Soc 87:1402-1404

Morton RA (1959) Ubiquinone. Nature 182:1764-1767

Norris SR, DellaPenna D, Barrette TR (1995) Genetic dissection of carotenoid synthesis in Arabidopsis defines plastoquinone as an essential component of phytoene desaturation. Plant Cell 7:2139-2149

Okayama S, Butler WL (1972) Extraction and reconstitution of photosystem 2. Plant Physiol 49:769-774

Pulles MPJ, Kerkhof PLM, Amesz J (1974) Photoreduction of plastoquinone to plastosemiquinone in spinach chloroplasts at $-40^{\circ} \mathrm{C}$. FEBS Lett 47:143-145

Rabinowitch E, Govindjee (1969) Photosynthesis. John Wiley \& Sons, NY, http://www.life.illinois.edu/govindjee/photosynBook. html

Redfearn ER, Friend J (1961a) Oxidation-reduction of plastoquinone in isolated chloroplasts. Nature 191:806-807

Redfearn ER, Friend J (1961b) Studies on plastoquinone. 1. Determination of the concentration and oxidation-reduction state of plastoquinone in isolated chloroplasts. Phytochemistry $1: 147-151$ 
Rumberg B, Schmidt-Mende PU, Siggel U, Skerra B, Witt HT (1965) Quantitative Kopplung der reaktionscyclen 1 und 2 im vollstandigen Reaktionssystem. Z Naturforsch 20b:1104-1116

Siggel U, Khanna R, Renger G, Govindjee (1977) Investigation of the absorption changes of the plastoquinone system in broken chloroplasts: the effect of bicarbonate-depletion. Biochim Biophys Acta 462:196-207

Smillie RM, Levine RP (1962) The photosynthetic electron transport chain of Chlamydomonas reinhardii. J Biol Chem 238:40584060

Snyder SW, Rustandi RR, Biggins J, Norris R, Thurnauer MC (1991) Direct assignment of vitamin K1 as the secondary acceptor A1 in photosystem one. Proc Natl Acad Sci USA 88:9895-9896

Sottocasa GL, Crane FL (1965) Components with redox potentiality in the neutral lipid fraction from beef heart mitochondria. Biochemistry 4:305-310

Stiehl HH, Witt HT (1969) Quantitative treatment of the function of plastoquinone in photosynthesis. Z Naturforsch 24b:1588-1598

Sun E, Barr R, Crane FL (1968) Comparative studies on plastoquinones. IV. Plastoquinones in algae. Plant Physiol 43:1935-1940

Sun IL, Sun EE, Crane FL, Morre DJ, Lindgren A, Low H (1992) Requirement for coenzyme $\mathrm{Q}$ in plasma membrane electron transport. Proc Natl Acad Sci USA 89:11126-11130

Tevini M, Lichtenthaler HK (1970) Untersuchungen uber die Pigment- und Lipochinonaustattung der zwei photosynthetischen Pigmentsystem. Z Pflanzenphysiol 62:17-32

Thomson RH (1957) Naturally occurring quinones. Academic Press, New York

Threlfal DR, Griffiths WT, Goodwin TW (1965) Isolation of two analogs of plastoquinone from senescent leaves of tobacco. Biochim Biophys Acta 102:614-618

Trebst A (1963) The role of benzoquinones in the electron transport system. Proc R Soc B 157:355-366

Trebst A, Eck H (1963) Zur rolle des Plastochinones bei der Photosynthese. Z Naturforsch 18b:694-700

Trebst A, Pistorious E (1965) Photosynthetische reaktionen in UVbestrahlen Chloreplasten. Z Naturforsch 20b:885-889
Trebst A, Eck H, Wagner S (1963) Effects of quinones and oxygen in the electron transport system of chloroplasts. In: Kok B, Jagendorf AT (eds) Photosynthesis mechanisms in green plants. Publ. No. 1145, National Research Council, Washington, DC, pp 174-194

Trenner NR, Arison BH, Erickson RB, Shunk CH, Wolf DE, Folkers K (1959) Coenzyme Q. VII. Structure studies on a plant quinone. J Am Chem Soc 81:2026-2027

Van Gorkom HJ (1974) Identification of the reduced primary acceptor of photosystem 2 as a bound semiquinone anion. Biochim Biophys Acta 347:439-442

Van Rensen JJS, Xu C, Govindjee (1999) Role of bicarbonate in the photosystem II, the water-plastoquinone oxido-reductase of plant photosynthesis. Physiol Plant 105:585-592

Wallwork JC, Pennock JF (1968) Nature of the plastoquinones. Chem Indus $1571-1572$

Williams JP (1968) Separation and estimation of quinones and $\alpha$ tocopherol from Vicia faba leaves. J Chromatogr 36:504-511

Witt HT (1971) Coupling of quanta, electrons, fields, ions, and phosphorylation in the functional membrane of photosynthesis. Quart Rev Biophys 4:365-477

Wolstenholme GEW, O'Connor C (eds) (1961) Quinones in electron transport. Churchill, London

Wood PM, Crane FL (1965) A requirement for reduced plastoquinone in the Hill reaction of extracted chloroplasts. Biochem Biophys Res Commun 20:274-278

Wood PM, Bhagavan HN, Crane FL (1966) Requirement for plastoquinone $\mathrm{A}$ in the Hill reaction of isolated chloroplasts. Plant Physiol 41:633-640

Wydrzynski TW, Satoh K (eds) (2005) Photosystem II: the lightdriven water:plastoquinone oxidoreductase. In: Govindjee (Series Editor), Advances in photosynthesis and respiration, vol 22. Springer, Dordrecht

Ytterberg AJ, Peltier J-B, van Wijk J (2006) Protein profiling of plastoglobules in chloroplasts and chromoplasts. A surprising site for differential accumulation of metabolic enzymes. Plant Physiol 140:984-997 